\title{
A rare case of atypical accessory bile duct: Luschka channel
}

\author{
(D) Yavuz Pirhan ${ }^{1}$, $\odot$ Havva Hande Keser Şahin ${ }^{2}$ \\ ${ }^{1}$ Department of General Surgery, Amasya University Faculty of Medicine, Amasya, Turkey \\ ${ }^{2}$ Department of Pathology, Hitit University Faculty of Medicine, Çorum, Turkey
}

Cite this article as: Pirhan Y, Keser Şahin HH. A rare case of atypical accessory bile duct: Luschka channel. Anatolian Curr Med J 2021; 3(1):

75-77.

\begin{abstract}
A 56-year-old male patient was admitted to our hospital with indigestion and abdominal bloating after eating. During routine surgery, a cystic artery, cystic duct, and an additional second duct were detected in the area of the Calot's triangle. Considering that this channel is the accessory bile duct entering the gallbladder during dissection, this structure, cystic duct and cystic artery were double clipped and cholecystectomy was completed. Bile duct injury is a serious complication of laparoscopic cholecystectomy (LC). Bile leakage from accessory duct of Luschka is rare. Anomalies of the bile ducts are common due to complex embryological stages of development. We wanted to share the presence of the atypical localized Luschka channel that we encountered during gallbladder surgery. In our case, during the dissection of the Calot's triangle, first, the Luschka channel was considered the main bile duct and after extensive dissection it was concluded that this structure was the Luschka channel. During laparoscopic cholecystectomy operations, we recommend that the cystic artery and canal be clipped after extensive dissection of the Calot's triangle or even the hepatic triangle in experienced hands.
\end{abstract}

Keywords: Anomalies of the biliary tract, cholecystectomy, accessory Luschka channel

\section{INTRODUCTION}

We wanted to share the presence of an atypical Luschka channel that we encountered during gallbladder surgery. Laparoscopic gallbladder surgery started in the first half of the 1990s and is rapidly expanding. Today, laparoscopic cholecystectomy is also widely used and has become the gold standard. Abnormalities of the biliary tract are common due to complex embryological developmental stages. It is known that the rate of anatomic variation in the biliary tract is $10 \% .90 \%$ of these variations are within the Calot's triangle, whose boundaries consist of the cystic duct, the lower liver, and the main hepatic duct (1). The Luschka channel, the most well-known of these variations, belongs to Type A in the Strasberg classification. Diagnosis is difficult because of late detection of Luschka channel injury. Non-surgical procedures are used primarily in the treatment, but if treatment fails, surgical treatment is performed. Our studies were carried out in accordance with the Helsinki declaration. Patients included in the study were informed about the procedures to be performed before and after the study. Informed consent was obtained from the patients.

\section{CASE REPORT}

A 56-year-old man presented with dyspepsia and postprandial bloating. As a result of blood tests and ultrasound, the patient underwent surgery for elective laparoscopic cholecystectomy with the diagnosis of many stones in the gallbladder, the largest of which was $1 \mathrm{~cm}$ in size. During routine outpatient surgery, a cystic artery, a cystic canal and an additional second canal were detected in the region of the Calot's triangle. During dissection, this duct was thought to be an accessory bile duct entering the gallbladder. Cholecystectomy was completed by double clipping this structure, cystic duct and cystic artery. As a result of examination of gallbladder specimen from the operating table, two biliary tracts and one artery which were very close to each other and unconnected were detected (Figure 1,2). There were no pathological results in the blood biochemistry tests performed on the 1 st and 2 nd postoperative days. The patient was discharged on the third postoperative day. No pathology was detected in the control at postoperative $15^{\text {th }}$ and $30^{\text {th }}$ days. 


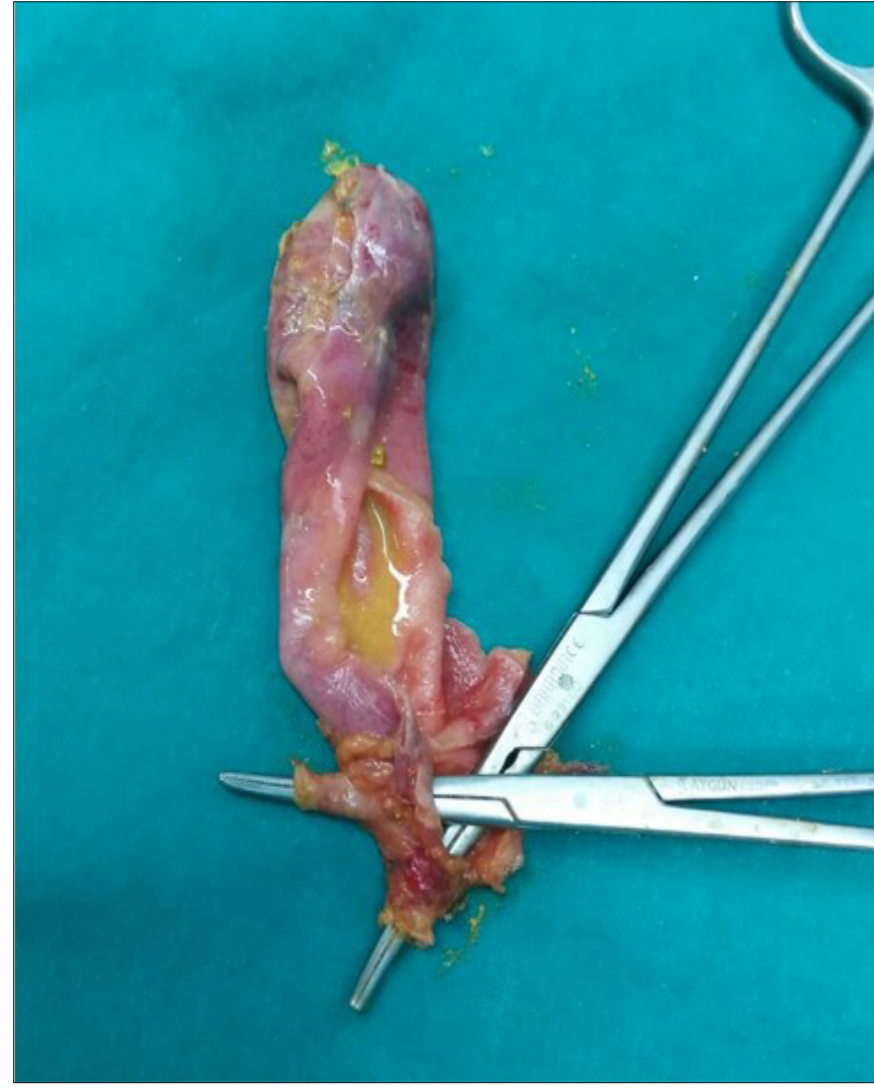

Figure 1. After cholecystectomy, the gallbladder is opened and two bile ducts are shown

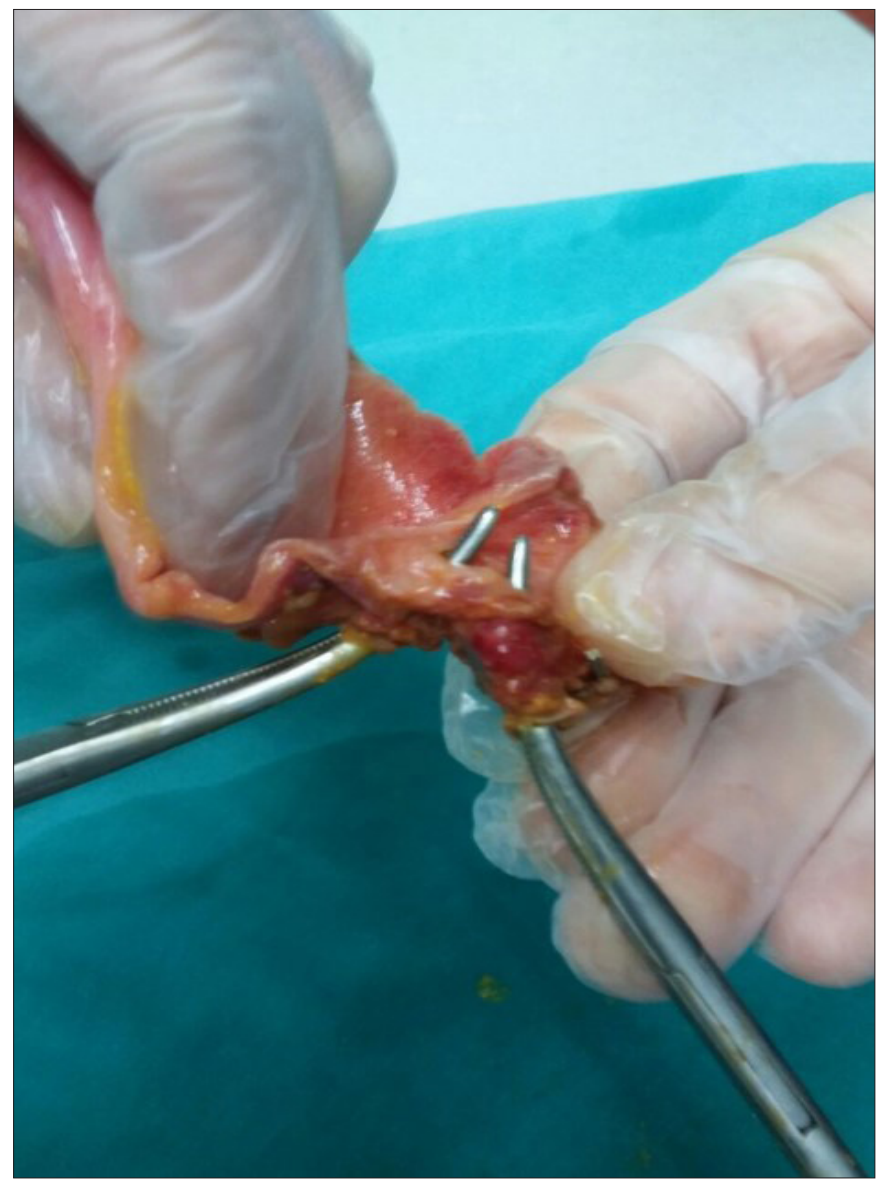

Figure 2. Opening the gallbladder after cholecystectomy and showing two bile ducts

\section{DISCUSSION}

Due to the complex stages of embryological development, anomalies of the biliary tract are common. It is known that the rate of anatomic variation in the biliary tract is $10 \% .90 \%$ of these variations are within the Calot's triangle, the boundary of which is called the cystic canal, lower liver and the main hepatic canal (1). Due to anatomic variations, iatrogenic biliary tract injuries (0.2-2\%) are still encountered during laparoscopy (2). Accessory bile ducts, which are expressed as Luschka, are still controversial in diagnosis and treatment due to their low clinical and incidence rates (3). Accessory Luschka channel was first defined in 1863 . The diameter of the channel is 1-2 $\mathrm{mm}$. Although it is located on the surface of the gallbladder, it does not enter the lumen of the gallbladder. It drains the subsegmental areas of the liver (4). In our case, the diameter of the Luschka channel was approximately $3-4 \mathrm{~mm}$ and about $1 \mathrm{~cm}$ superior to the cystic duct, coming out of the gallbladder and entering the liver. The actual incidence is still unknown. In the literature, rates ranging from $1-50 \%$ are given (5). It is included in Type A in the Strasberg classification (6). The mechanism of injury is related to the application of laparoscopic cholecystectomy at a deeper level than it should. Late presentation of the peritonitis due to the small diameter of the accessory Luschka channel and low leakage biliary flow is responsible for the late presentation of the clinic (7). Another important reason is that there is no realization of injury during surgery. For these reasons, it is the most difficult type of injury to detect during laparoscopy and the latest clinical cause of all bile duct injuries. The clinic usually begins to become apparent about 10 days after surgery (7). Biochemical parameters do not deteriorate in the early period, but change in the table in which sepsis is settled. In Luschka injuries, serum bilirubin values are generally within normal limits. The clinic therefore develops slowly, and patients are generally accepted with symptoms of abdominal pain and sepsis due to bile leakage. The diagnostic stages begin with suspecting the presence of the Luschka channel, then the diagnosis is made using abdominal ultrasonography, magnetic resonance cholangiopancreaticography (MRCP) and endoscopic retrograde cholangiopancreaticography (ERCP) methods, respectively. In the treatment, it is possible to expect closure of the accessory canal by drainage of the bile by using percutaneous transhepatic cholangiography (PTC) in the presence of enlarged intrahepatic biliary tract in proximal Luschka cases $(8,9)$. In cases that do not improve despite these treatments, drainage of bile by open or laparoscopic surgery and ligation of the canal detected during surgery $(10,11)$. 


\section{CONCLUSION}

In the present case, during the dissection of Calot's triangle, the Luschka was thought to be the main bile duct first, and after extensive dissection, it was concluded that this structure was Luschka. During laparoscopic cholecystectomy operations, we recommend that the cystic artery and cystic canal be clipped after the wide dissection of the Calot's triangle or even the hepatic triangle in experienced hands.

\section{ETHICAL DECLARATIONS}

Informed Consent: Written informed consent was obtained from all participants who participated in this study.

Referee Evaluation Process: Externally peer-reviewed.

Conflict of Interest Statement: The authors have no conflicts of interest to declare.

Financial Disclosure: The authors declared that this study has received no financial support.

Author Contributions: All of the authors declare that they have all participated in the design, execution, and analysis of the paper, and that they have approved the final version.

\section{REFERENCES}

1. Senapati A, Wolfe JH. Accessory cystic duct--an operative hazard. J R Soc Med. 1984; 77: 845-6.

2. Spanos CP, Syrakos T. Bile leaks from the duct of Luschka (subvesical duct): a review. Langenbecks Arch Surg 2006; 391: 4417.

3. Parampalli U, Helme S, Asal G, et al. Sinha Accessory cystic duct identification in laparoscopic cholecystectomy Grand Rounds 2008; 8: 40-2.

4. Aoki T, Imamura H, Sakamoto Y, et al. Bile duct of Luschka connecting with the cystohepaticduct: The importance of cholangio graphy during surgery. Am J Roentgenol 2003; 180: 694-6.

5. Frakes JT, Bradley SJ. Endoscopic stent placement for biliary leak from an accessory duct of Luchska after laparoscopic cholecystectomy. Gastrointest Endosc 1993; 39: 90-2.

6. Strasberg SM, Hetl M, Soper NJ. An analysis of the problem of biliary injury during laparoscopy cholecystectomy. J Am Coll Surg 1995; 180: 101-25

7. Russell JC, Walsh SJ, Mattie AS, et al. Bile duct injuries 1989-1993. Arch Surg 1996; 131: 382-8

8. Prat F, Pelletier G, Ponchon T, et al. What role can endoscopy play in the management of biliary complications after laparoscopic cholecystectomy? Endoscopy 1997; 29: 341-8.

9. Mergener K, Strobel JC, Suhocki P, et al. The role of ERCP in diagnosis and management of accessory bile duct leaks after cholecystectomy. Gastrointest Endosc 1999; 50: 527-31.

10. Stewart L, Way LW. Laparoscopic bile duct injuries: timing of surgical repair does not influence success rate. A multivariate analysis of factors influencing surgical outcomes. HPB (Oxford) 2009; 11: 516-22.
11. Bektas H, Schrem H, Winny M, Klempnauer J. Surgical treatment and outcome of iatrogenic bile duct lesions after cholecystectomy and the impact of different clinical classification systems. Br J Surg 2007; 94: 1119-27. 